\title{
FEEDING HONEY-BEE COLONIES (APIS MELLIFERA CARNICA POLL.) AND DETECTION OF HONEY ADULTERATION
}

\author{
A. Kandolf Borovšak ${ }^{a *}$, N. Ogrinc ${ }^{b}$, N. LiLeK ${ }^{a}$ and M. KorošEC \\ aSlovenian Beekeepers Association, Brdo pri Lukovici 8, SI-1225 Lukovica. Slovenia \\ ${ }^{\mathrm{b} J o z ̌ e f ~ S t e f a n ~ I n s t i t u t e, ~ J a m o v a ~ 39, ~ S I-1000 ~ L j u b l j a n a . ~ S l o v e n i a ~}$ \\ 'Biotechnical Faculty, University of Ljubljana, Jamnikarjeva 101, SI-1000 Ljubljana. Slovenia
}

(Received: 8 March 2015; accepted: 1 August 2015)

Honey is a valued substance that has excellent nutritional value. However, it is a vulnerable product, with the possibility of adulteration at each stage of its production and processing, in terms of direct and indirect adulteration. The objective of this study was to determine whether feeding of honey-bee colonies with honey-bee candy results in honey adulteration. The physicochemical properties of honey samples were determined, and the ability to discriminate between authentic and adulterated honey was studied. The physicochemical properties evaluated were water and hydroxymethylfurfural content, electrical conductivity, $\mathrm{pH}$ value, acidity, foreign enzymes, and stable isotopes. Sensory and melissopalynological analysis were also performed on 39 honey samples. $\beta$-fructofuranosidase activity, $\delta^{13} \mathrm{C}$ (honey), difference between the $\delta^{13} \mathrm{C}$ of the honey and of its protein (i.e. $\Delta \delta^{13} \mathrm{C}$ ) were identified as the most important to discriminate between authentic and adulterated honey samples. The results of the study indicate that honey-bee feeding practices might have an influence on honey and its adulteration.

Keywords: adulteration detection, honey, honey-bee feeding, foreign enzymes, stable isotopes

Honey is a valued sweet and viscous substance that has excellent nutritional value. However, it is a vulnerable product, with the possibility of adulteration at each stage of its production and processing (White \& Winters, 1989; Padovan et al., 2003). For instance, honey can be adulterated with fraudulent intent by feeding the honey bees during the honey flow, as indirect adulteration, or by the addition of sugar after the honey harvesting, which can lead to higher honey production through direct adulteration (ZÁBrodSKÁ \& VorLOVÁ, 2014). In our experience, adulteration can also be unintentional, such as when caused by mistakes made by the beekeepers, or misuse of their technology, particularly when there is the need to feed the honey-bee colonies before winter or before the honey-flow season (our unpublished data). Due to bad weather conditions, the beekeepers sometimes have to feed the honey bees during early spring (STANDIFER, 1980), usually with a honey-bee candy, which can result in adulteration of the honey (our unpublished data).

Testing for honey adulteration can be done through analysis of the sensory and melissopalynological properties, and of the different physicochemical parameters of the honey. These can include the sugar and amino-acid profiles, the diastase activity, and the content of hydroxymethylfurfural (HMF) and proline (CоттE et al., 2003). Evaluation can also include the presence of foreign enzymes (e.g., $\beta$-fructofuranosidase, $\beta / \gamma$ amylase) in the honey, which are used in inverted sugar syrup production (VALKOv et al., 2010).

Several analytical techniques can be used for the detection of honey adulteration, including chromatography (FöldHÁzI, 1994; CoRdELla et al., 2003; 2005; CABAÑERO et al., 2006; Puscas et al., 2013) and spectrometry (Gallardo-Velázquez et al., 2009). The

\footnotetext{
* To whom correspondence should be addressed.

Phone:+386-40-436 514; fax: +386-1-7296132; e-mail: andreja.kandolf@czs.si
} 
introduction of stable carbon isotope ratio mass spectrometry was a milestone in the detection of more sophisticated adulteration of honey with syrups. The method was also improved using an isolated honey protein as an internal standard, which has enhanced the sensitivity and thus lowered the limit of detection for $\mathrm{C}_{4}$ sugars from ca. 20\% to 7\% (DONER \& White, 1977).

The majority of the research into honey is concentrated on the means of direct and indirect adulteration with different varieties of sugar syrup (CORDELLA et al., 2005; RuizMATUTE et al., 2010; GULER et al., 2007; 2014), while there remains the problem of not knowing what happens to the honey after using honey-bee candy in honey-bee feeding. The objective of the present study was to determine whether bee colony feeding in spring with a honey-bee candy can cause honey adulteration, and which analytical methods are the most useful to determine such adulteration.

\section{Materials and methods}

\subsection{Honey-bee colonies}

Thirty honey-bee colonies (Apis mellifera carnica Pollmann, 1879) were settled into a bee house in the Gorenjska region (Slovenia). The technique of reversing the combs from the brood chamber to the honey supers was used to prevent swarming. The honey-bee colonies were divided in the various groups. As the controls, honey-bee colonies from groups 21 and 31 were used, which did not receive any food in spring. Groups 22 and 32 received winter feeding in the supers at ca. $3 \mathrm{~kg}$, groups 23 and 24 received $5 \mathrm{~kg}$ honey-bee candy in total, group 331 received $0.75 \mathrm{~kg}$, group 332 received $1.5 \mathrm{~kg}$, and group 333 received $2.5 \mathrm{~kg}$ honeybee candy in total. The honey-bee sugar candy Stimulans contained yeast, while Apifonda did not. The division of these colonies into the various groups is presented in Table 1.

Table 1. Plan of the experimental layout for each year

\begin{tabular}{lcccc}
\hline Group code & Year & $\begin{array}{c}\text { Colonies } \\
(\mathrm{n})\end{array}$ & $\begin{array}{c}\text { Feeding } \\
\text { Honey-bee candy per } \\
\text { feeding }\end{array}$ \\
\hline 21 & 2012 & 9 & None & NA \\
31 & 2013 & 6 & None & NA \\
22 & 2012 & 9 & ca. $3 \mathrm{~kg}^{\mathrm{a}}$ & NA \\
32 & 2013 & 6 & ca. $3 \mathrm{~kg}^{\mathrm{a}}$ & NA \\
331 & 2013 & 6 & honey-bee candy & ca. $0.15 \mathrm{~kg}$ \\
332 & 2013 & 6 & honey-bee candy & ca. $0.33 \mathrm{~kg}$ \\
333 & 2013 & 6 & honey-bee candy & ca. $0.50 \mathrm{~kg}$ \\
23 & 2012 & 9 & honey-bee candy & ca. $1.00 \mathrm{~kg}$ \\
24 & 2012 & 2 & honey-bee candy & ca. $1.00 \mathrm{~kg}$ \\
\hline
\end{tabular}

a: Remains of winter feeding in supers; ${ }^{\text {b: }}$ commercial honey-bee candy: (Stimulans) from 18 April to 15 May;

c: commercial honey-bee candy: (Apifonda) from 18 April to 15 May; NA: not applied

\subsection{Sampling}

Honey samples were taken from the honey harvested on 11 June in both 2012 and 2013. Samples within the groups in 2012 were collected together. In 2012, within one group, only three samples were collected, with the honey from three of the colonies harvested in the same 
tank, except samples from group 24, which were collected separately, and thus 11 samples were collected. In 2013, the samples from each hive were collected separately, although no honey was harvested from colonies 1 and 2, and so 28 samples were collected.

\subsection{Microscopic analysis}

Qualitative and quantitative melissopalynological analyses were carried out according to the standardised methods of melissopalynology (Von DER OHe et al., 2004). The Shannon-Weaver diversity indices were calculated.

\subsection{Sensory analysis}

All of the samples were coded with a random three-digit code. Three trained assessors determined the sensory characteristics of the honeys on the basis of previously memorised standards for polyfloral honey. The scoring method had a maximum of 27 points, which were applied for the evaluation of the colour, brightness, odour, taste, aroma persistence, and aroma typicality of the honey samples. Non-trained assessors (32 consumers of honey) were used to determine hedonically whether the honeys were authentic. The consumers tasted the honey samples and circled YES or NO on the score sheet according to their opinion on the honey authenticity. Each honey sample was assessed by at least three consumers, in a random order.

\subsection{Physicochemical analysis}

Water content, electrical conductivity, $\mathrm{pH}$ value, free acidity, diastase activity, and HMF content were analysed according to the standardised methods of the International Honey Commission (Bogdanov et al., 1997). The qualitative melissopalynological and sensory analysis and the data on the electrical conductivity were used to also determine the botanical origins of the honey samples.

\subsection{Analysis of stable isotopes-ISCIRA method}

The carbon isotope ratios $\left({ }^{13} \mathrm{C} /{ }^{12} \mathrm{C}\right)$ were determined for the honey and protein samples according to the AOAC method 998.12 (AOAC, 1999) as well as to PADOVAN and co-workers (2003).

\subsection{Foreign enzymes}

The presence of $\beta$-fructofuranosidase and $\beta / \gamma$ amylase in the honey samples was investigated by Intertek Food Service GmbH (Germany).

All of the analyses within one parameter were conducted at the same time within three days.

\subsection{Statistics}

The statistical analysis was carried out using SPSS 21.0 version for Windows (IBM). Basic descriptive statistics, analysis of variance (ANOVA), and non-parametric tests were used. Multivariate analysis was carried out using linear discriminant analysis and principal component analysis. 


\section{Results and discussion}

According to the electrical conductivity, sensory and melissopalynological characteristics, all of the honey samples were of polyfloral nectar origin. All of the samples were in line with values for the physicochemical parameters set by Council Directive 2001/110/EC (EC, 2001) relating to honey. In terms of the full parameters analysed, most of the samples were classified as authentic, except some of the samples listed below. The mean data and the basic statistics obtained from the analyses are given in Table 2 .

\subsection{Microscopic analysis}

According to the experimental procedures (Table 1), it was expected that the honey samples from groups 21 and 31 (i.e., with no spring feeding) would have higher amounts of pollen and might have more variability in the plant species. Honey bees also collect pollen for their bee bread, which can fall into the honey during the honey harvesting (MAURIzIO, 1975). The presence of bee bread in the honey might be higher due to the reversing of the honey combs from the brood chamber to the honey supers, as in our case, because the bee bread is saved near the bee brood (MAurizio, 1975). Due to this, the pollen spectrum and the quantity of pollen are not reliable methods for the definition of honey adulteration.

In both of the sampled honeys from 2012, where the honey bees received feeding (i.e., groups 23, 24), a large number of yeast cells were observed, while in the samples from groups 21 and 22 (i.e., no feeding), there were no yeast cells. Although similar in 2013, yeast cells were identified in only five of the samples where the bees received feeding (i.e., three in group 331 , and one each in groups 332,333 ). The presence of yeast in honey is potentially a strong indication of honey adulteration, because of the use of yeast in honey-bee candy preparations.

\subsection{Sensory analysis}

The tests carried out for the authenticity of the honeys regarding their sensory properties according to the consumers did not reveal any differences between the honey samples from the different experimental groups. However, the trained assessors scored the samples from groups 21 and 32 (i.e., no spring feeding) significantly higher, and the samples from group 332 (i.e., spring feeding with $0.33 \mathrm{~kg}$ paste/feeding) significantly lower than the other honey samples.

\subsection{Physicochemical analysis}

The electrical conductivities of honeys are mainly dependent on their source, which was also seen in the present study. The samples from 2012 had significantly higher electrical conductivities than the samples from 2013. The honey water content, $\mathrm{pH}$ value, and diastase activity were also influenced by the season of the harvesting of the honey samples (i.e., 2012 vs. 2013), rather than by the experimental feeding of the bees. Samples from the feeding groups had the lowest values of electrical conductivity (i.e., groups $331,332,333$ ), $\mathrm{pH}$ value (i.e., groups $24,331,332,333$ ), and diastase activity (i.e., groups $23,331,332,333$ ).

Although the diastase activity and HMF content were analysed for both 2012 and 2013, these cannot be directly compared as the ages of the honeys at the time of these analyses were not the same. However, the comparisons of the HMF content within the samples from 2013 showed significant differences between the samples of group 31 (i.e., no feeding) and all of 
KANDOLF BOROVŠAK et al.: FEEDING HONEY BEES AND HONEY ADULTERATION

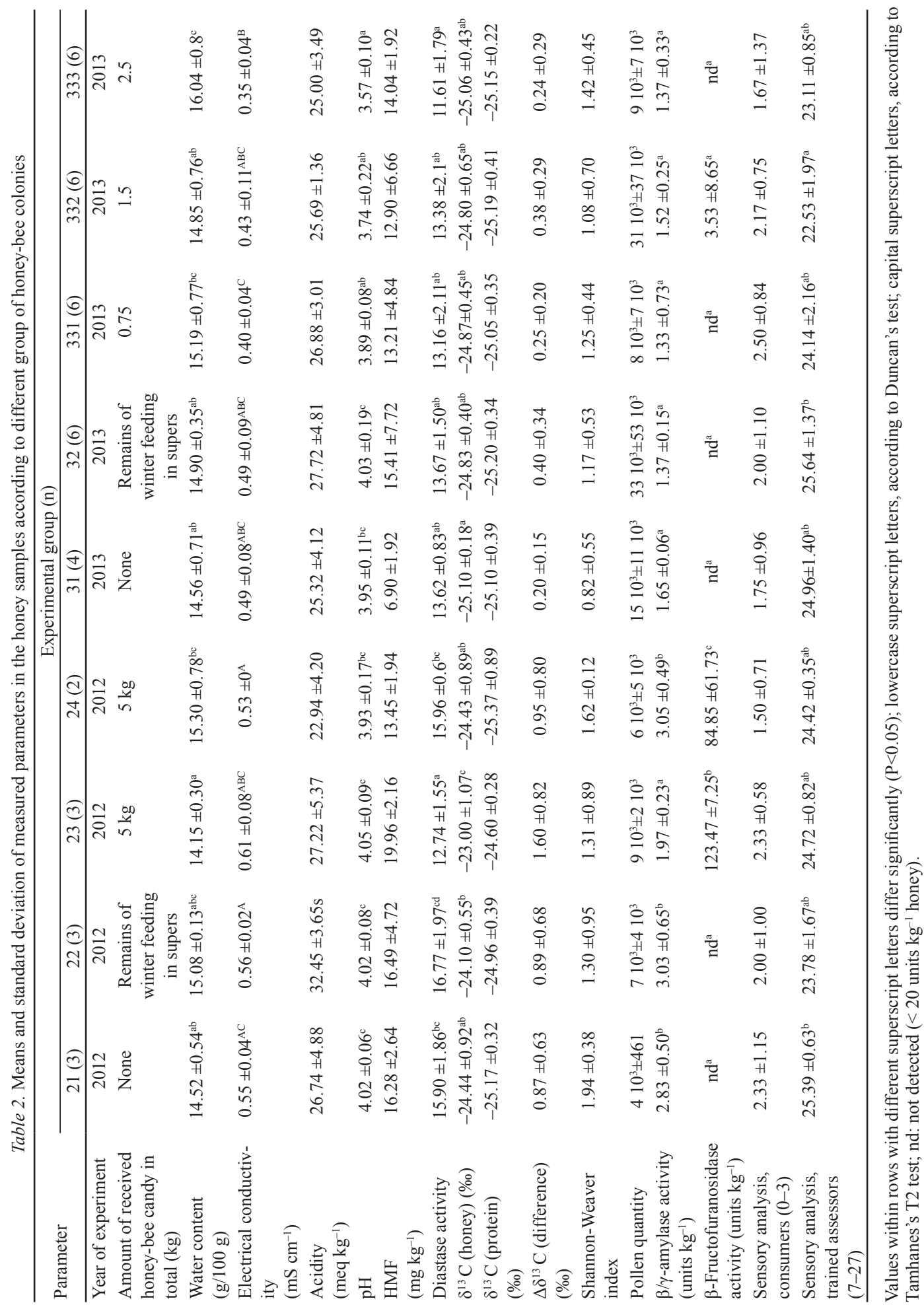


the other experimental conditions. Indeed, supplementary feeding with sucrose and inverted sucrose syrup has been shown to affect the water and HMF content, diastase activity, free acidity and $\mathrm{pH}$ value of honeys (ÖZCAN et al., 2006).

\subsection{Analysis of stable isotopes}

The samples from 2013 had more negative $\delta^{13} \mathrm{C}$ (honey). Pure honey has been shown to have more negative $\delta^{13} \mathrm{C}$ than syrup (PADOvan et al., 2003). The samples from group 31 had the highest, and statistically significant, negative values (i.e., for no feeding), and the samples from group 23 had the lowest negative values (i.e., for spring feeding with $1 \mathrm{~kg}$ paste / feeding), which corresponds to their foreign enzyme activity and to similar previous studies (Guler et al., 2014).

The difference between the $\delta^{13} \mathrm{C}$ of the honey and of the honey protein (i.e., $\Delta \delta^{13} \mathrm{C}$ ) exceeded $1 \%$ in six samples, as one sample in groups 21,22 , and 24 , and in all three samples in group 23 (Table 2), which indicates the detection of honey adulteration. According to the design of our study, the samples from groups 31 and 21 (i.e., reversing with no feeding) should be authentic honey; however, in group 21 , one sample appeared to be adulterated according to the $\Delta \delta^{13} \mathrm{C}$.

Basing on $\Delta \delta^{13} \mathrm{C}$ exceeding 1\%, KROPF and co-workers (2010) suspected adulteration in six samples out of 271 analysed samples (i.e., $2 \%$ of their honey samples), and CоттE and co-workers (2007) in 3 out of 97 honey samples (i.e., 3\% of samples). However, later, some of these apparently adulterated samples were believed not to be adulterated, because of the controls that the beekeepers were under, and because other honey analyses did not show any adulteration. These studies concluded that some reservations can be formulated about the validity of the ISCIRA method, and the present study can confirm their findings. Thus, it is important to find new methodologies for the detection of honey adulteration (COTTE et al., 2007). Separation techniques coupled to isotope ratio mass spectrometry have been suggested to be more powerful (CABAÑERO et al., 2006). The same can also be concluded in the present study for samples from the no-feeding group (i.e., group 21).

\subsection{Foreign enzymes}

The honey harvested from the colonies that were fed honey-bee candy in 2012 (i.e., groups $23,24)$ had significantly higher levels of $\beta$-fructofuranosidase activity, while in the other samples (i.e., groups 21,22 ) there was none. For the $\beta$-fructofuranosidase, where $>20$ units/ $\mathrm{kg}$ honey has been used to show adulteration (ZÁBrodSKÁ \& VorLoví, 2014), some of these values were high, at 124 units $/ \mathrm{kg}$ for group 23, and 85 units $/ \mathrm{kg}$ for group 24, thus indicating adulteration of these honeys. In the samples from 2013, there were no significant differences in the foreign enzyme activities among the honeys from the no-feeding and the fed colonies, with only one sample in group 332 (i.e., spring feeding in 2013 with $0.33 \mathrm{~kg} /$ feeding of commercial honey-bee candy) that showed $\beta$-fructofuranosidase activity $(21.2$ units $/ \mathrm{kg})$, which again indicated adulteration of the honey (Table 2). Detection of $\beta$-fructofuranosidase activity appears to be a successful method to reveal adulteration of honey by the indirect adulteration method of feeding the honey-bee colonies with candy made of sugar, while FeI and co-workers (2012) identified honey adulteration using rice syrup based on determination of $\gamma$-amylase. 


\subsection{Multivariate analysis}

When the values for the 16 parameters determined for the honey samples were processed according to the principal component analysis, the parameters identified as the most important for discrimination among these experimental groups of samples were: $\beta$-fructofuranosidase activity, $\beta / \gamma$ amylase activity, $\delta^{13} \mathrm{C}$ (honey), $\Delta \delta^{13} \mathrm{C}$, electrical conductivity, and $\mathrm{pH}$ value (Fig. 1). The electrical conductivity of honey has also been indicated as one of the most important discriminating parameters in other studies (GULER et al., 2007).

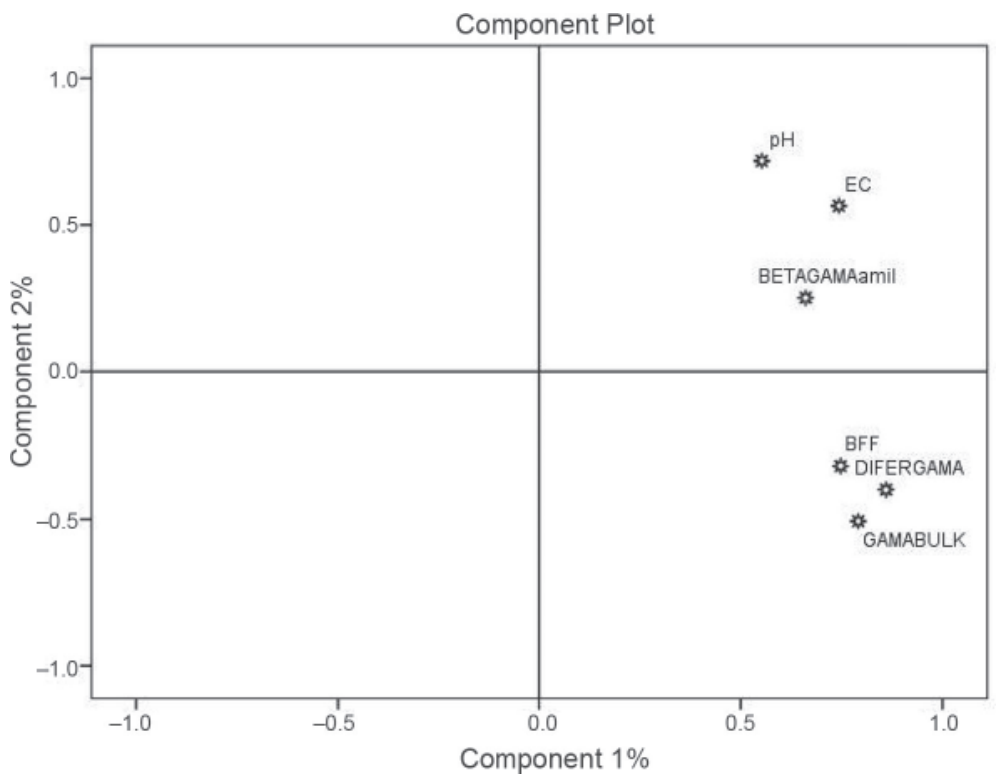

Fig. 1. Determination of the most important parameters for honey discrimination according to principal component analysis: $\mathrm{pH}$ value, electrical conductivity, $\beta$-fructofuranosidase, $\beta / \gamma$ amylase, $\delta^{13} \mathrm{C}$ (honey), and $\Delta \delta^{13} \mathrm{C} \cdot \mathrm{pH}: \mathrm{pH}$ value; EC: electrical conductivity; $\mathrm{BFF}$ : $\beta$-fructofuranosidase;

BETAGAMAamil: $\beta / \gamma$ amylase; GAMABULK: $\Delta{ }^{13} \mathrm{C}$ honey; DIFERGAMA: $\Delta^{13} \mathrm{C}$

\subsection{Linear discriminant analysis}

Linear discriminant analysis (Fig. 2) revealed that on the basis of the parameters analysed, $97.4 \%$ of the samples were correctly classified into their actual group. However, $16.7 \%$ of the samples in groups 32 and 333 were not correctly classified.

As seen in Figure 2, the samples in groups 23 and 24, and also groups 21 and 22, differed significantly across the analysed parameters from the samples in the other groups. 


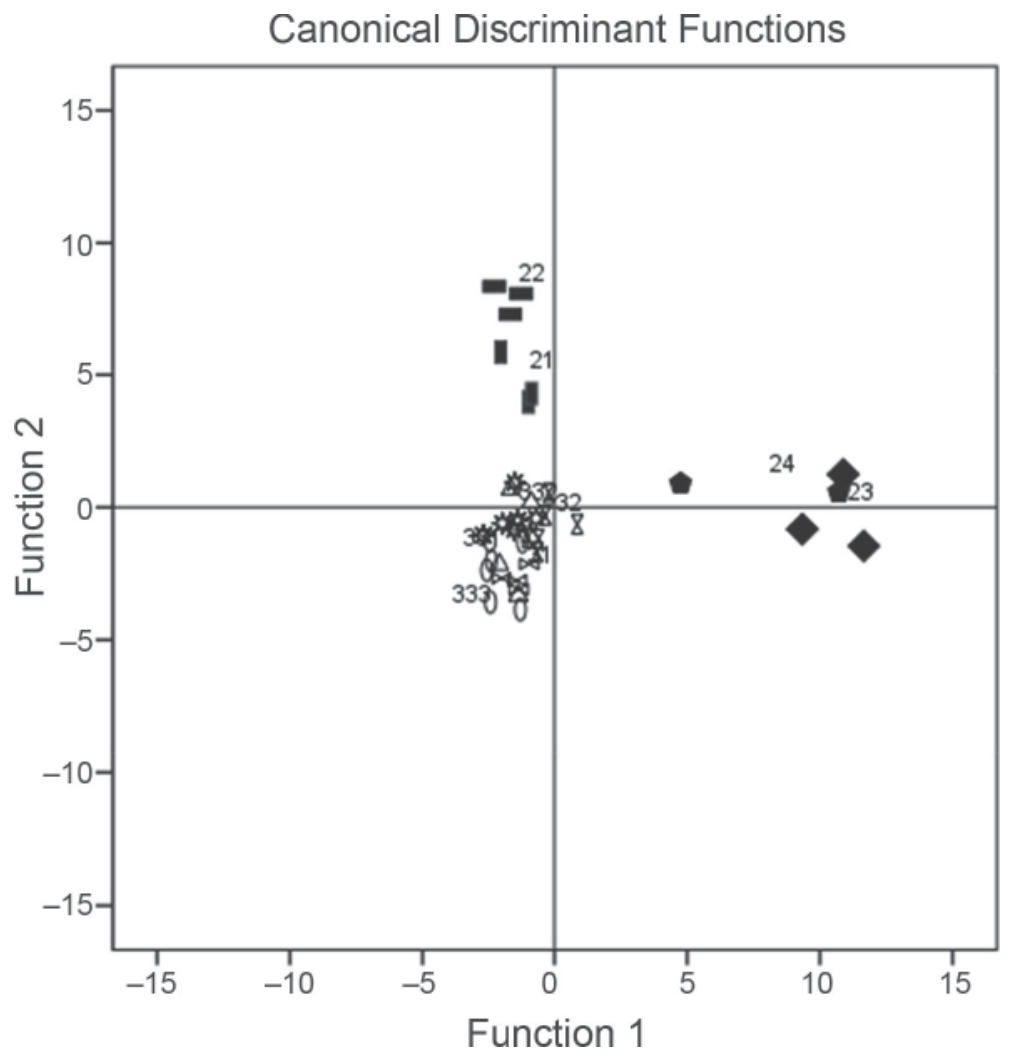

Fig. 2. Discrimination among the sample groups according to the linear discriminant analysis 【: $21 ;: 22 ;: 23 ;: 24 ; \infty: 31 ; 8: 32 ; \Delta: 331 ;$; $: 332 ; 0: 333$

\section{Conclusions}

It is difficult to detect honey adulteration when honey-bee colonies are fed with sugar, because the honey-bees produce the adulterated honey in the same manner as for the natural honey flow. The sensory analysis and the pollen spectrum did not indicate these samples as adulterated. On the basis of the present study, the most successful analyses to reveal honey adulteration after feeding honey-bee colonies with honey-bee candy are the activities of foreign enzymes in the honey and the determination of the $\delta^{13} \mathrm{C}$ values. The presence of yeast in honey might represent a strong indication of honey authenticity, and this should be correlated with the foreign enzyme activities from further analyses.

Feeding honey-bee colonies in spring and also reversing the honey combs can present a risk of honey adulteration; however, this risk can be large or small depending on other factors, such as the honey-flow season and the bee-colony strength, and especially the amount of added honey-bee candy for feeding. 
This study is a part of the research doctoral dissertation supported by Innovative schemes for co-financing of doctoral studies that is financed by the European Union through the European Social Fund. We also acknowledge the support from the Programme of Public Advisory Service for beekeepers supported by the Ministry of Agriculture, Forestry and Food, and by the Apiculture Programme for 2013.

\section{References}

AOAC (1999): Official methods of analysis, 988.12, $\mathrm{C}_{4}$ plant sugars in honey. Internal standard stable carbon isotope ration method. Int. Gaithersburg, MD USA, Chapter 44, pp. 27-30.

Bogdanov, S., Martin, P. \& Lüllman, C. (1997): Harmonised methods of the European Honey Commission. Apidologie (extra issue), 1-59.

Cabañero, A.I., Recio, J.L. \& Rupérez, M. (2006): Liquid chromatography coupled to isotope ratio mass spectrometry: a new perspective on honey adulteration detection. J. Agr. Food Chem., 5, 9719-9727.

Cordella, C.B.Y., Militão, J.S.L.T., Clément, M.-C. \& CABrol-Bass, D. (2003): Honey characterization and adulteration detection by pattern recognition applied on HPAEC-PAD profiles. 1. Honey floral species characterization. J. Agr. Food Chem., 51, 3234-3242.

Cordella, C., Militão, J.S.L.T., Clément, M.-C., Drajnudel, P. \& Cabrol-Bass, D. (2005): Detection and quantification of honey adulteration via direct incorporation of sugar syrups or bee-feeding: preliminary study using high-performance anion exchange chromatography with pulsed amperometric detection (HPAEC-PAD) and chemometrics. Anal. Chim. Acta, 531, 239-248.

Cotte, J.F., Casabianca, H., Chardon, S., Lhéritier, J. \& Grenier-Loustalot, M.F. (2003): Application of carbohydrate analysis to verify honey authenticity. J. Chromatogr. A., 1021, 154-155.

Cotte, J.F., Casabianca, H., Lhéritier, J., Perrucchietti, C., Sanglar, C., Waton, H. \& Grenier-Loustalot, M.F. (2007): Study and validity of ${ }^{13} \mathrm{C}$ stable carbon isotopic ratio analysis by mass spectrometry and ${ }^{2} \mathrm{H}$ sitespecific natural isotopic fractionation by nuclear magnetic resonance isotopic measurements to characterize and control the authenticity of honey. Anal. Chim. Acta, 582, 125-136.

Doner, L.W. \& White, J.W. (1977): ${ }^{13} \mathrm{C} /{ }^{12} \mathrm{C}$ ratio relatively uniform among honeys. Science, 197, 891-892.

EC (2001): Council Directive 2001/110/EC of 20 December 2001 relating to honey. O.J., L(10), 47-52

Fei, X., Wu, B., Shen, C., Zhang, R., Ding, T. \& LI, L. (2012): Determination of exogenous gamma-amylase residue in honey. (in Chinese). Chinese J. Chrom, 30, 777-781.

FöLDHÁzI, G. (1994): Analysis and quantitation of sugar in honey of different botanical origin using high performance liquid chromatography. Acta Alimentaria, 23, 299-311.

Gallardo-Velázquez, T., Osorio-Revilla, G., Loa, M.Z. \& Rivera-Espinoza, Y. (2009): Application of FTIRHATR spectroscopy and multivariate analysis to the quantification of adulterants in Mexican honeys. Food Res. Int., 42, 313-318.

Guler, A., Bakan, A., Nisbet, C. \& Yavuz, O. (2007): Determination of important biochemical properties of honey to discriminate pure and adulterated honey with sucrose (Saccharum officinarum L.) syrup. Food Chem., 105, $1119-1125$

Guler, A., Kocaokutgen, H., Garipoglu, A.V., Onder, H., Ekinci, D. \& Biyik, S. (2014): Detection of adulterated honey produced by honeybee (Apis mellifera $\mathrm{L}$.) colonies fed with different levels of commercial industrial sugar $\left(\mathrm{C}_{3}\right.$ and $\mathrm{C}_{4}$ plants $)$ syrups by the carbon isotope ratio analysis. Food Chem., 155, 155-160.

Kropf, U., Golob, U., Nečemer, M., Kum, P., Korošec, M., Bertoncelj, J. \& Ogrinc, N. (2010): Carbon and nitrogen natural stable isotopes in Slovene honey: Adulteration and botanical and geographical aspects. J. Agr. Food Chem., 58, 12794-12803.

Maurizio, A. (1975): Microscopy of honey. -in: Crane, E. (Ed.), Honey, a comprehensive survey. Heinemann, London, pp. 240-266.

Özcan, M., Arslan, D. \& CEYlan, D.A. (2006): Effect of inverted saccharose on some properties of honey. Food Chem., 99, 24-29.

Padovan, G.J., De Jong, D., Rodrigues, L.P. \& Marchini, J.S. (2003): Detection of adulteration of commercial honey samples by the ${ }^{13} \mathrm{C} /{ }^{12} \mathrm{C}$ isotopic ratio. Food Chem., 82, 633-636.

Puscas, A., Hosu, A. \& Cimpiou, C. (2013): Application of a newly developed and validated high-performance thinlayer chromatographic method to control honey adulteration. J. Chromatogr. A., 1272, 132-135.

Ruiz-Matute, A.I., Rodríguez-Sánchez, S., Sanz, M.L. \& Martínez-Castro, I. (2010): Detection of adulterations of honey with high fructose syrup from inulin by GC analysis. J. Food Compos. Anal., 23, 273-276. 
StANDIFER, L.N. (1980): Honey bee nutrition and supplemental feeding. -in: USDA (Ed.): Beekeeping in the United States. Agricultural handbook, no. 335, pp. 39-45.

Valkov, V., Elflein, L. \& Raezke, K.P. (2010): Determination of foreign enzymes in honey to detect adulterations with sugar syrups. Intertek Food Service, GmbH, pp. 1-5. http:/www.pcelinjak.hr/OLD/images/stories/test2/ aaa/publication_foreign_enzymes_05.02.10.pdf (last accessed: 1 August 2015)

Von der Ohe, W., Persano-Oddo, L., Piana, M.L., Morlot, M. \& Martin, P. (2004): Harmonized methods of melissopalynology. Apidologie, 35, 18-25.

White, J.W. \& Winters, K. (1989): Honey protein as internal standard for stable carbon isotope ratio detection of adulteration of honey. J. AOAC Int., 72, 907-911.

ZÁBrodská, B. \& Vorlová, L. (2014): Adulteration of honey and available methods for detection - a review. Acta Vet. Brno, 83, 85-102. 